\title{
O SINDICALISMO DEIXOU A CRISE PARA TRÁS? um novo ciclo de greves na década de 2000
}

\author{
Armando Boito Jr." \\ Paula Marcelino
}

\begin{abstract}
O objetivo deste texto é retomar, de modo preliminar e indicativo, o debate sobre a crise ou o declínio histórico do movimento sindical. A questão que queremos levantar é a seguinte: a atividade sindical, na década de 2000, é um indicativo de que o sindicalismo brasileiro superou a crise? O nosso texto analisa o ciclo de greves em curso no Brasil a partir do ano de 2004, destacando, dentre outros elementos, o número de greves e de grevistas, o caráter ofensivo dessas greves e as vitórias que os trabalhadores vêm obtendo em suas reivindicações. Defendemos a hipótese, ainda sob investigação, de que a atividade sindical no Brasil nos anos 2000 é um indicador muito forte do equívoco da tese do declínio histórico do sindicalismo.

PALAVRAS-CHAVE: sindicalismo, greves, crise, Brasil.
\end{abstract}

\section{OPROBLEMA}

O objetivo deste texto é retomar, de modo preliminar e indicativo, um debate que mobilizou os estudiosos, observadores e ativistas do movimento sindical nas décadas de 1980 e 1990. Naquela época, escreveu-se muito sobre a crise e, em alguns casos, sobre o declínio histórico do movimento sindical. A questão que queremos levantar é a seguinte: à luz da atividade sindical na década de 2000, o que podemos, retrospectivamente, dizer sobre aquelas teses? Na década de 2000, o sindicalismo deixou a crise para trás? Podemos afirmar que a atividade sindical da década em curso está desmentindo a tese do declínio histórico do sindicalismo?

Com efeito, as décadas de 1980 e 1990 presenciaram um período de considerável refluxo da

\footnotetext{
* Professor Titular do Departamento de Ciência Política da Unicamp.

Cidade Universitária Zeferino Vaz. Instituto de Filosofia e Ciências Humanas. Caixa Postal 6110. Cep: 13083-970, Campinas - São Paulo. boito@uol.com.br

* * Pós-doutoranda em Ciência Política na Unicamp. paula.marcelino@ymail.com
}

ação sindical nos maiores países europeus, nos Estados Unidos e em parte dos países da América Latina (Rodrigues, 2002). ${ }^{1} \mathrm{O}$ impacto desse movimento de refluxo entre os estudiosos do tema foi grande. Os diagnósticos emitidos variaram. Uns falaram em crise do sindicalismo e outros, mais ousados, chegaram a concluir que o sindicalismo entrara numa fase de declínio histórico, iniciando uma marcha para o fim ou para uma situação em que passaria a existir apenas vegetativamente.

De fato, na maioria dos países europeus e latino-americanos, pode-se observar uma moderação na luta sindical. No Brasil, segundo Pochmann (1998, p. 161), os anos 1990 são marcados por, pelo menos, cinco alterações importantes: queda na quantidade de greves, redução na taxa de sindicalização, proliferação "administrativa" do número de sindicatos - fenômeno possibilitado pela estrutura sindical corporativa de Estado ainda existente no Brasil -, fragmentação das negociações e diminuição da quantidade de cláusulas acordadas. Segundo Rodrigues:

${ }^{1}$ Dizemos em parte dos países porque no Brasil, por exemplo, a década de 1980 é marcada por uma ampla mobilização sindical. 
... os sindicatos, em todo o mundo, vivem hoje uma situação muito difícil, expressa na queda do número e da proporção de filiados e no declínio das taxas de greve, dois fenômenos indicativos do enfraquecimento do sindicalismo como instituição e do poder sindical como ator político (2002, p.11).

A situação do sindicalismo, ainda segundo Rodrigues, apontaria muito mais para um declínio desse tipo de ação do que para uma crise. A diferença entre as duas situações é que uma crise poderia ser superada e, eventualmente, promover um salto qualitativo. Já o declínio é algo irreversível, como o envelhecimento. A introdução da automação e da informatização prejudicou o sindicalismo, pois ele tinha como alicerce, fundamentalmente, os trabalhadores manuais. O declínio só não foi mais profundo porque, ao contrário do que aconteceu com o setor privado, no Brasil e nos outros países capitalistas do mundo, houve um crescimento do sindicalismo dos funcionários públicos. A entrada em cena desses novos sindicatos significou certa reativação do sindicalismo como um todo, pois foi capaz de introduzir um pouco de dinamismo para as estruturas consolidadas e acomodadas dos sindicatos (Rodrigues, 2002, p.108).

A tese do declínio do sindicalismo foi colocada em debate no Brasil pelo livro de Rodrigues, em 2002. Contudo, essa não é uma ideia original na bibliografia sobre o tema. Antes, Baumard e Blanchot já sustentavam o seguinte: “... compreendemos que, mais que uma conjuntura desfavorável, é a essência mesma do sindicalismo que está atualmente em crise” (1994, p.23). Os autores recuperam essa tese, por sua vez, de Pierre Rosanvallon, em livro de 1988 (La Question Syndicale). De resto, a ideia de uma crise do sindicalismo ou de seu declínio não só não é exclusividade de autores brasileiros, como tampouco é um debate recente. Segundo Mouriaux (1994), a noção de crise do sindicalismo é antiga e perpassa, de uma forma ou de outra, toda a história do movimento sindical. Já em 1910, segundo o autor, a Confédération General du Travail - CGT -francesa fez uma enquete sobre a crise do sindicalismo. As explicações surgidas nessa pesquisa foram as mais variadas: rotinização da vida sindical, inabilidade das lideranças, forma de agir dos anarquistas, etc. O sindicalismo, no geral, passava por uma fase de transição entre as corporações de ofício e a indústria. Hoje, os argumentos comuns para explicar o fenômeno que uns chamam de crise e outros de declínio do sindicalismo se referem às condições econômicas a partir das quais atuam os sindicatos, à maior ou menor disponibilidade dos governos para tolerar a existência ou negociar com eles e fazem, fundamentalmente, referência às mudanças tecnológicas - que seriam causa de desemprego, da diminuição do peso do setor secundário da economia na geração empregos - e às alterações no perfil da força de trabalho.

A discussão sobre crise ou declínio do sindicalismo está diretamente ligada, nos países do capitalismo ocidental, ao contexto da fase neoliberal desse sistema e da reestruturação das empresas. Se a parcela conservadora dos pesquisadores do tema deixou de lado os estudos sobre o sindicalismo, por considerá-lo anacrônico numa “economia de mercado", parece razoável afirmar que uma parcela dos estudiosos progressistas também cedeu, de alguma forma, às análises que atenuam o papel da luta sindical das classes trabalhadoras. Não seria gratuito afirmar que a tese sobre o declínio histórico da luta sindical bem como a ênfase unilateral e genérica na idéia de crise do sindicalismo podem ter contribuído para desarmar os ativistas e dirigentes do movimento sindical.

\section{ODEBATE}

Examinemos esse debate um pouco mais de perto. $^{2}$

Caire (1990) sistematiza um conjunto de explicações para a crise do sindicalismo, dizendo que se trata de um movimento que se desdobra em três momentos: crise de adesão, crise de militantismo e crise da imagem do sindicalismo. Segundo esse autor, a crise seria mais ampla e mais profunda

A discussão da bibliografia que apresentamos a seguir baseia-se no trabalho de Paula Marcelino (2008). 
que a vivida no período após a Segunda Guerra. Primeiro, porque ela teria uma duração maior; depois, porque o desemprego do final do século XX apresentava-se como um fenômeno mais massivo que o que se verificava no período subsequente à Segunda Guerra. No que se refere às mutações nos comportamentos individuais, o autor destaca três fontes importantes: os jovens, as mulheres e os desempregados. Esses últimos, mesmo quando têm a possibilidade de se sindicalizar - como ocorre, por exemplo, na Alemanha -, criariam um problema de identidade para o movimento sindical, pois ele sempre se baseou em trabalhadores empregados, de estabilidade financeira para as organizações. A organização de trabalhadores desempregados imporia duas ordens de problemas para o movimento sindical: primeiramente, esse tipo de trabalhador teria dificuldade em contribuir financeiramente para a manutenção do sindicato e, em segundo lugar, essas organizações teriam dificuldades para definir métodos de luta e uma estratégia reivindicativa eficaz, visto que a greve só pode ser empreendida por quem está empregado. ${ }^{3}$

Alguns dos principais fatores que, segundo Rodrigues (2002), precipitariam o que o autor considera um declínio histórico do sindicalismo seriam: a descentralização da barganha, ou seja, a pulverização das categorias profissionais em diversos sindicatos; a incidência maior da negociação por local de trabalho, prática cada dia mais comum pela pressão das próprias empresas e pela dificuldade de os sindicatos mobilizarem grandes contingentes de trabalhadores; flexibilização da utilização da força de trabalho, com os aumentos de jornada, as contratações temporárias e a degradação de direitos trabalhistas.

Embora não apresente dados específicos, Rodrigues (2002) acredita que tem aumentado o desinteresse dos trabalhadores pelo sindicato. Isso se daria porque,

Diante do risco de diminuição do emprego, os sindicatos tendem a moderar as demandas e, as-

${ }^{3}$ Os mesmos argumentos são levantados para explicar também a crise do sindicalismo na Inglaterra, por Poirier e Ravier (1990). sim, a se mostrarem menos úteis para os empregados. Consequentemente, os custos [como o pagamento de mensalidades e as medidas de represália patronal, AB/PM] passam a não compensar as vantagens que a sindicalização possa eventualmente trazer.

Além disso, acrescenta Rodrigues,

... as conquistas sindicais anteriores diminuem, ironicamente, a necessidade atual dos sindicatos. Acrescentam-se a isso as novas políticas de relações humanas das grandes empresas, mais integrativas e democráticas (2002, p.275).

Deixando de lado o pressuposto, no mínimo duvidoso, segundo o qual as novas formas de produção e organização do trabalho democratizariam as relações de poder dentro das empresas (Rodrigues, 2002), ou que elas permitiriam uma maior autonomia do trabalhador (Leite, 1994), é preciso reconhecer que as idéias e fatos que levam Rodrigues (2002) e outros autores a concluírem que o sindicalismo estaria em um processo de declínio histórico é um encadeamento lógico de idéias que parece, no seu conjunto, fazer sentido: mudanças tecnológicas e organizacionais que levam ao desemprego que, por sua vez, ocasiona o descrédito na capacidade de o sindicalismo reverter a situação, o que provoca a desfiliação e a desindentificação sindical. Há outros elementos que compõem esse quadro de crise ou de declínio: a burocratização do funcionamento dos sindicatos, a desconfiança dos trabalhadores frente às lideranças sindicais (Labbé; Croisat, 1992) e a politização ou partidarização dos sindicatos (Mouriuax, 2006); mas eles entram de maneira secundária nas explicações gerais sobre a crise ou o declínio do sindicalismo.

Os motivos da crise ou do declínio histórico do sindicalismo, arrolados pela bibliografia que aborda o tema, podem ser classificados em cinco tipos: a) motivos ou causas de ordem econômica, como o desemprego e o crescimento econômico baixo, que são características do modelo capitalista neoliberal, particularmente na Europa e na América Latina;

b) motivos ou causas referentes à reorganização dos processos de trabalho e das formas de contratação: 
introdução de mecanismos flexibilização do aparato produtivo, ampliação da terceirização, trabalho temporário, etc;

c) motivos ou causas que versam sobre o funcionamento da organização e do movimento sindical: burocratização dos sindicatos, vinculação com partidos políticos, etc.

d) motivos ou causas de ordem ideológica e política: ascensão da ideologia liberal, individualismo crescente, perda da referência socialista e comunista, etc.

e) motivos ou causas da ordem da composição da força de trabalho: maior resistência à atuação sindical demonstrada por jovens e mulheres, dois segmentos que tiveram participação bastante ampliada nas últimas décadas, no mercado de trabalho.

\section{UMA PRIMEIRA AVALIAÇÃO DO DEBATE}

Consideramos, quanto a nós, que os dados indicam que houve, de fato, um refluxo do movimento sindical em escala internacional, quando comparamos a situação do sindicalismo nas décadas de 1980 e 1990 com a situação que esse movimento vivia na década de 1970. O texto de Rodrigues (2002), embora tenha, na nossa avaliação, caracterizado esse refluxo erroneamente, como tentaremos apontar, ao denominá-lo um declínio histórico, teve o mérito de evidenciar em dados o refluxo efetivo da luta sindical. Esse refluxo incluiu o sindicalismo brasileiro, embora a tendência à queda da luta sindical tenha chegado aqui algum tempo depois de já ter se instalado nos maiores países da Europa. Por ora, basta citarmos um dado: no segundo lustro da década de 1980, a média anual de greves no Brasil atingiu o número de 2203; já para o período 1991-1997, a média anual de greves caiu para cerca de 930 (Noronha et al., 1998).

Contudo, caracterizar o refluxo como crise estrutural ou declínio é outro passo. As regiões mais populosas do planeta, situadas no Centro e no Sul do continente asiático, apenas nas últimas décadas ingressaram no processo de industrializa- ção. Os conflitos trabalhistas, ainda em caráter présindical, isto é, espontâneos e resolvidos por via judicial, estão crescendo na China, que é o principal país da região. Não é o caso de nos perguntarmos se não teremos, no futuro próximo, um movimento sindical de trabalhadores industriais na China? Ademais, e voltando para o caso da Europa e do Brasil, se observadas as curvas de longo prazo, podemos afirmar que o sindicalismo mantém-se estável ou em ascensão. Trata-se, portanto, de um erro analítico chegar a um prognóstico de tendência irreversível de declínio do sindicalismo, fazendo projeções de longo prazo a partir apenas da análise das tendências de curto prazo. Quando se compara a atividade sindical (greves, taxas de sindicalização, etc.) da década de 1990 com a da década de 1970 nos países da Europa, o resultado é uma queda; mas, se a comparação se dá com a década de 1960, a constatação será contrária. Isso vale também para o caso brasileiro.

Duas questões são incontornáveis: como caracterizar esse refluxo? Quais foram as suas causas?

Daquelas cinco ordens de motivos ou causas enumeradas no item anterior deste texto, as duas primeiras, referentes aos fatores econômicos (desemprego, crescimento baixo) e à reestruturação do processo de trabalho (novas tecnologias, novos métodos de produção) e das formas de contratação, ocupam um papel de destaque na bibliografia. Em outras palavras, a crise do sindicalismo, para uns, ou seu declínio histórico, para outros, tem sua explicação centrada na irreversibilidade daquilo que seria identificado como uma nova ordem social, resultante de mudanças econômicas e tecnológicas, principalmente. Diante desse diagnóstico, seríamos, em boa lógica, obrigados a deduzir que não haveria saída para o sindicalismo (Boito Jr., 2003). Ou seja, a maioria dessas análises, quando não ignora, minimiza o papel da conjuntura política e ideológica na qual agem as forças sociais em presença e, inclusive, o movimento sindical, como um movimento reivindicativo dos trabalhadores assalariados. Assim, incorre-se no equívoco que consiste em analisar a classe operária e o sindicalismo separadamente do processo 
político nacional e internacional.

Analisada com cuidado a história do movimento operário, veremos que os trabalhadores mais organizados sindicalmente da fase anterior do capitalismo (período do Estado de Bem-estar e do desenvolvimentismo) puderam se beneficiar da expansão do movimento socialista em escala internacional ao longo da primeira metade do século $\mathrm{XX}$. Embora o movimento sindical e o movimento socialista sejam dois movimentos distintos, eles podem entreter, dependendo da situação histórica, uma relação de fortalecimento mútuo, e foi justamente isso o que ocorreu em grande parte dos países ao longo do século XX. Já os novos setores da classe operária e demais classes trabalhadoras iniciaram sua luta sindical numa conjuntura política muito desfavorável, marcada pela crise do movimento socialista e pela ofensiva neoliberal em escala internacional. Por isso, é muito cedo para dizermos, simplesmente, que os setores emergentes da classe operária e dos assalariados de classe média não apresentam propensão à sindicalização.

Ao já exposto contra a ideia de uma irreversibilidade da crise, soma-se o fato de que há, na história do sindicalismo, vários exemplos de setores que não tinham propensão aparente à sindicalização e que, em determinadas condições históricas, aderiram massivamente a essa forma de organização e de luta. Poderíamos citar três casos muito importantes para a história do sindicalismo internacional e bastante conhecidos: o surgimento dos denominados Sindicatos Gerais na Inglaterra do final do século XIX, que arregimentaram as massas trabalhadoras da indústria e também do setor de serviços, rejeitadas pelas trade-unions, posto que esses sindicatos se baseavam apenas nos trabalhadores qualificados (Marx; Engels, 1972); o surgimento dos denominados sindicatos industriais nos EUA das décadas de 1920 e 1930, que arregimentaram a massa de trabalhadores não-qualificados do setor industrial, rejeitados pela American Federation of Labor (AFL) (Guerrin, 1977); e o sindicalismo de classe média, que arregimentou para a ação sindical os trabalhadores de escritório e do Estado, considerados, até mea- dos do século XX, trabalhadores infensos a qualquer apelo sindical (Lockwood, 1962; Boito, 2007). Nesses três casos, a incorporação massiva desses novos setores à luta sindical representou um novo vigor no movimento reivindicativo dos trabalhadores.

Nas teses sobre o declínio do sindicalismo, também há outro pilar mal colocado: a tese de que as classes trabalhadoras são hoje mais fragmentadas e heterogêneas do que em outras fases do capitalismo. Em primeiro lugar, podemos nos perguntar se essa tese não subestimaria a heterogeneidade das classes trabalhadoras ao longo de toda a história do capitalismo. O historiador Eric Hobsbawm insiste na ideia de que, na passagem do século XIX para o século XX, foi o movimento operário que criou a unidade da classe operária, pois, do ponto de vista socioeconômico, essa classe era por demais heterogênea e fragmentada (Hobsbawm, 2009).

A tese da fragmentação como causa fundamental da crise do sindicalismo ignora, também, que há, no capitalismo contemporâneo, um processo contrário à fragmentação que é o de homogeneização entre os trabalhadores de classe média e os operários; entre os trabalhadores de diferentes nacionalidades; entre os trabalhadores e as trabalhadoras. Assim, coexistem processos de heterogeneização e de homogeneização dentro de um mesmo período histórico e de uma mesma formação social. Por que esses autores consideram somente a segmentação quando discutem o destino do sindicalismo no mundo? Fragmentação da classe trabalhadora sempre houve. Mas, para que essa fragmentação afete positiva ou negativamente a luta sindical, são necessárias certas condições ligadas à conjuntura política, à história de luta dos diversos sindicatos etc.

Em um esforço de análise mais geral, podemos afirmar que, na fase do capitalismo neoliberal, os processos de segmentação da classe trabalhadora, decorrentes das novas formas de organização e contratação da força de trabalho, impõem dificuldades importantes para a ação sindical. A segmentação dificulta a ação sindical, mas, dependendo da conjuntura, ela pode desempenhar o 
papel contrário e ser o motor ou um dos fatores de união e revolta dos trabalhadores. Alguns exemplos podem ser apontados nesse sentido: a ação sindical de trabalhadores subcontratados por centenas de empresas e nas mais variadas funções dentro da Refinaria de Paulínia (São Paulo-BR) se mostra vigorosa e ofensiva, conquistando, anos a fio, ganhos reais de salários e ampliação de direitos (Marcelino, 2008); a greve, de 84 dias de duração, que mobilizou cerca de oito mil funcionários de 40 empresas prestadoras de serviços à Refinaria de Duque de Caxias/RJ (Reduque, Petrobras), reivindicando isonomia salarial, participação nos lucros e resultados (PLR) e reajuste salarial (Dieese, 2007); a greve prolongada e vitoriosa dos $185 \mathrm{mil}$ trabalhadores da United Parcel Service (UPS), Estados Unidos, em 1997. A mobilização sindical uniu trabalhadores precários e "estáveis" na luta por um único contrato de trabalho (Fantasia, 1997); na França, entre os anos de 2000 e 2003, surgiram várias lutas nos setores de fast food, comércio e limpeza. A maioria dos trabalhadores era formada por jovens em trabalhos precários. Alguns desses movimentos foram: em 2000, greve no Mac Donald's do Boulevard Saint-Germain; em 2001, greve na Pizza Hut do Ópera; em 2002, greve de 112 dias no Mac Donald's de Strasbourg SaintDenis para a reintegração de trabalhadores demitidos - reivindicação atendida; ainda em 2002, greve na FNAC da Champs-Elysées; entre março de 2002 e fevereiro de 2003, greve das trabalhadoras da limpeza do grupo Accor, empregadas no Hotel Arcade (Perrin, 2004). A homogeneidade não garante a unidade nem a heterogeneidade é sinônimo de desorganização. A segmentação atual entre os trabalhadores pode ser um obstáculo de monta para sua organização, mas não é mais que isso.

\section{O CICLO DE GREVES DE 2004-2008 NO BRASIL}

O que a situação atual da organização e da luta sindical no Brasil pode nos dizer sobre o debate acerca da crise ou do declínio histórico do sindicalismo? Ou melhor, que reflexões podemos fazer sobre a situação atual tendo em vista aquele debate?

Na nossa avaliação, vivemos, pelo menos desde 2004, uma conjuntura de recuperação da atividade sindical no Brasil. Na base, a ação grevista mantém-se num nível razoavelmente alto, e a grande maioria das greves tem permitido ganhos reais de salários; na cúpula do movimento, a disputa política acirrou-se com o surgimento de cinco novas centrais sindicais. ${ }^{4}$ Essa recuperação da luta sindical pode ser tomada como um indicador da vitalidade do sindicalismo como movimento social.

Iremos tomar, neste artigo, a atividade grevista como uma porta de entrada para analisar a situação do movimento sindical brasileiro na década de 2000. A nossa escolha se justifica por duas razões. A primeira é uma razão de ordem prática: os dados mais sistemáticos e gerais que temos sobre o sindicalismo brasileiro na década de 2000 são os dados sobre greves, coletados pelo Departamento Intersindical de Estatística e Estudos Socioeconômicos, o Dieese. A segunda é uma razão sociológica: a greve não é a única ação importante e pertinente do movimento sindical, mas é, seguramente, uma de suas ações mais contundentes e de maior visibilidade política e social. Façamos, a esse respeito, alguns esclarecimentos.

${ }^{4}$ Entre 2004 e 2007, cinco novas centrais sindicais foram criadas: Conlutas, criada em 2004 como dissidência da Central única dos Trabalhadores (CUT) e fortemente vinculada ao Partido Socialista dos Trabalhadores Unificado (PSTU); Intersindical, de 2006, também dissidência da CUT e com forte presença do Partido Socialismo e Liberdade (PSOL) e do Partido Comunista Brasileiro (PCB); Nova Central Sindical (NCST), formalizada em 2005 por um grupo de sindicatos, federações e confederações que se consideraram isolados durante o Fórum Nacional do Trabalho; Central dos Trabalhadores e Trabalhadoras do Brasil (CTB), formada por antigas correntes da CUT, uma ligada ao Partido Comunista do Brasil (PC do B) e outra ao Partido Socialista Brasileiro (PSB); e, por fim, União Geral dos Trabalhadores (UGT), criada em 2007 como resultado da fusão da Confederação Geral dos Trabalhadores (CGT), da Social Democracia Sindical (SDS) e da Central Autônoma dos Trabalhadores (CAT). E certo que essa onda de novas centrais sindicais não pode ser vista, em sua totalidade, como expressão de pujança do sindicalismo na década de 2000. A NCST e a UGT representam, fundamentalmente, a parte mais conservadora do sindicalismo brasileiro - conhecida, tradicionalmente, pela designação de "pelegos". Contudo, a criação da Conlutas, da Intersindical e da CTB expressa a luta entre correntes socialistas e democráticas pela hegemonia no movimento sindical brasileiro. 
A história do sindicalismo mostra que a atividade grevista não apresenta uma trajetória linear. As greves ocorrem em ciclos, com fases ascendentes, de estabilização e de declínio. Esses ciclos apresentam perfis característicos e fatores determinantes variados. O perfil das greves de cada ciclo e os fatores que as determinam estão, na maioria das vezes, relacionados. Um ciclo poderá ter a greve de massa como característica, outro, a greve localizada; um poderá atingir números excepcionalmente elevados na atividade grevista, outro, manter-se num padrão mais modesto; aquele poderá representar uma ação política contra um regime ditatorial, esse, uma resposta à corrosão dos salários pela alta taxa de inflação na economia.

Poderíamos citar aqui o ciclo de greves ocorrido no Brasil entre 1978 e 1992, que atingiu números excepcionalmente elevados na atividade grevista (número de greves, volume de horas não trabalhadas, número total e médio de grevistas, etc.), constituindo-se, na verdade, em um ciclo que poderíamos considerar excepcional (Noronha, et al., 1998). ${ }^{5}$ Esse ciclo assemelhou-se a um ciclo ocorrido, na mesma época, na Espanha. O Brasil e a Espanha, países que reuniam condições excepcionais, foram, na época, uma espécie de campeões mundiais da atividade grevista. Eram países que vinham de um crescimento capitalista forte e prolongado, que se encontravam sob regimes ditatoriais em crise e que apresentavam um recrudescimento da taxa anual de inflação. Nessas condições econômicas e políticas, os trabalhadores espanhóis e brasileiros puderam expandir e revitalizar suas organizações sindicais e partidárias, e a ação sindical, identificada que era com o processo de luta democrática, contava com a simpatia ou a condescendência de grande parte da população.

Na década de 2000, sendo outras as condi-

${ }^{5}$ Em artigo de 2009, Noronha refaz sua análise e chama todo o longo período de 1978 a 1997 como o primeiro grande ciclo de greves no Brasil e os anos que o sucederam, de 1998 a 2007, ou seja, os anos de governo de Fernando Henrique Cardoso e Luiz Inácio Lula da Silva, como o período de normalização. Essa normalidade seria caracterizada pelo fato de as greves terem, na opinião do autor, adquirido a dimensão característica de todos os países democráticos: “... um instrumento coletivo de pressão e negociação do elo mais fraco da relação entre empregados e empregadores.” (Noronha, 2009). ções econômicas e políticas, será também outro o perfil do ciclo de greves. Ao dizer isso, queremos advertir o leitor para o fato de que o ciclo excepcional de greves de 1978-1992 não pode ser tomado como unidade de medida para avaliar a dimensão e a natureza da crise sindical iniciada na década de 1990 e para a recuperação, que acreditamos ser real, do sindicalismo na década de $2000^{6}$. A maior parte da década de 1980 e a primeira metade da década de 1990 foram marcadas, como se sabe, por uma taxa de inflação muito elevada, que beirou, em mais de uma conjuntura, a situação de hiperinflação. Já, na década de 2000, a taxa de inflação tem se mantido baixa. Ora, o aumento do número de greves em resposta à corrosão dos salários pela inflação, ou a sua diminuição em decorrência de uma relativa estabilização dos preços, não podem ser considerados, sem mais, indicadores de força ou de fraqueza do movimento sindical.

Outra advertência importante, como já indicamos, é que a greve não é o único elemento para avaliar o movimento sindical, e a leitura do significado sociológico e político da ação grevista não é uma operação simples. Alguns pesquisadores europeus têm destacado que a estatística de greve descura a importância de outros tipos de conflito que têm ocorrido, com maior frequência nos últimos anos, no interior das empresas. Esses tipos de conflito, que nem sempre levam à organização de um movimento grevista, ganharam importância, justamente, com as novas formas de organização do processo de trabalho, oriundas da reestruturação das empresas capitalistas. Na França atual, cresceu a prática daquilo que lá se designa com o termo debrayage, para indicar a paralisação de apenas um setor da empresa, mas um setor cuja inserção estratégica permite comprometer a produção ou o funcionamento da empresa como um todo (Beroud et al., 2008).

${ }^{6}$ Alguns estudiosos do sindicalismo incorreram nesse erro. Trata-se de um erro semelhante ao que fora cometido pelos estudiosos do movimento estudantil. Na década de 1980, comparando a situação do movimento estudantil de então com as ações empreendidas pelos estudantes na crise excepcional de 1968, muitos estudiosos concluíram, erroneamente, que o movimento estudantil havia acabado. (Martins Filho, 1987). 


\section{ORIGEM DO NOVO CICLO DE GREVES}

Acreditamos que, se tomarmos a atividade grevista como indicador, poderemos afirmar que o sindicalismo brasileiro encontra-se, na década de 2000, em plena fase de recuperação. ${ }^{7}$

Para iniciar, digamos uma palavra sobre as prováveis causas da recuperação do movimento sindical brasileiro. Essas causas podem ser as seguintes:

a) uma retomada, ainda que tímida, do crescimento econômico;

b) ligeira recuperação do emprego;

c) o fato de a inflação dos alimentos estar atingindo taxas superiores à taxa média de inflação, isto é, há uma taxa de inflação, ocultada pela inflação média, que atinge mais pesadamente os trabalhadores;

d) a existência de um regime democrático;

e) o fato de a equipe governamental bem como as presidências e diretorias de empresas estatais serem compostas, no período dos mandatos presidenciais de Lula da Silva, por pessoas oriundas, em grande parte, do movimento sindical-no quadriênio 2004/ 2007, o Governo Federal e as empresas estatais negociaram com mais de $90 \%$ das greves deflagradas pelofuncionalismo público federal e pelos trabalhadores das empresas estatais;

f) o desgaste da ideologia neoliberal que aparece na eleição de Lula e nos novos governos de esquerda e centro-esquerda na América Latina;

g) a concorrência política entre as centrais sindicais brasileiras, cujo número e variedade de orientações político-ideológicas cresceram, como já dissemos, entre 2004 e 2007.

h) uma década de experiência, por parte do movimento sindical no Brasil, com os chamados "processos flexíveis" da reestruturação produtiva capitalista ea construção de alternativas de ação diante dela.

Ou seja, nossa hipótese é que as alterações

${ }^{7}$ Utilizaremos, nas nossas considerações sobre esse ciclo de greves, as pesquisas do Dieese - Sistema de Acompanhamento de Greves (SAG). Tal pesquisa, retomada em 2004 pelo Dieese, baseia-se na coleta de dados realizada pelos técnicos daquela instituição junto aos grandes jornais e aos jornais sindicais - tanto em suas versões impressa quanto eletrônica. O resultado das pesquisas de greve é publicado na série do Dieese intitulada Estudos e Pesquisas, e boa parte dos textos pode ser encontrada na rede mundial de computadores. na conjuntura econômica, política e ideológica podem ter propiciado uma recuperação do sindicalismo. Se isso for verdadeiro, estará evidenciada a improcedência daquela postura determinista, apresentada criticamente na primeira parte deste trabalho, que vaticinava o declínio histórico do sindicalismo. O que estamos sugerindo é que, mudada a conjuntura, muda também a situação do movimento sindical.

\section{PERFIL DO NOVO CICLO DE GREVES}

Vejamos, agora, algumas das características do perfil da atividade grevista no ciclo atual que merecem ser destacadas.

1. O número de greves e de grevistas vem se mantendo num patamar relativamente elevadopouco mais de 300 greves por ano até 2007 e uma média anual de 1,5 milhão de grevistas. No ano de 2008, o ano da crise econômica, esses números saltaram para 411 greves e 2 milhões de grevistas.

Nota-se a participação majoritária do setor público - funcionalismo público e empregados de empresas estatais. Apenas o ano de 2008 registrou um número de greves maior na esfera privada (224) que na esfera pública (184). Observa-se, porém, que a participação dos trabalhadores do setor privado, mesmo antes de 2008, foi elevada e crescente ao longo do quinquênio 2004-2008, quer consideremos o número de greves ou o número de grevistas. É importante destacar, para que conheçamos melhor as características do atual ciclo de greves, que esse nível de atividade grevista ainda é inferior ao verificado na década de 1990, quando a média anual foi de cerca de 900 greves (Noronha, et al., 1998). Mais à frente, diremos algo sobre essa diferença entre o número de greves nas décadas de 1990 e de 2000. Por ora, vejamos os dados do quinquênio 2004-2008.

2. As greves têm sido, em sua maioria, greves ofensivas, ${ }^{8}$ isto é, por novas conquistas, e não greves para recuperar ou evitar perdas. As reivin-

${ }^{8}$ Nós chamamos greves "ofensivas" o que o Dieese denomina, em seus documentos, "greves propositivas". Em 
Tabela 1 - Distribuição de greves nas esferas pública e privada. Brasil - 2004 a 2008

\begin{tabular}{|c|c|c|c|c|c|c|c|c|c|c|}
\hline \multirow{2}{*}{ Esfera/Setor } & \multicolumn{2}{|c|}{2004} & \multicolumn{2}{|c|}{2005} & \multicolumn{2}{|c|}{2006} & \multicolumn{2}{|c|}{2007} & \multicolumn{2}{|c|}{2008} \\
\hline & $\mathrm{n}^{\circ}$ & $\%$ & $\mathrm{n}^{\circ}$ & $\%$ & $\mathrm{n}^{\circ}$ & $\%$ & $\mathrm{n}^{\circ}$ & $\%$ & $\mathrm{n}^{\circ}$ & $\%$ \\
\hline Pública & 185 & 61,3 & 162 & 54,2 & 165 & 51,6 & 161 & 50,9 & 184 & 44,8 \\
\hline Func. público & 158 & 52,3 & 8,9 & 138 & 24 & 46,2 & 8,0 & 145 & 20 & 45,3 \\
\hline Empresas estatais & 27 & 6,3 & 140 & 21 & 44,3 & 6,6 & 155 & 29 & 37,7 & 7,1 \\
\hline Privada & 114 & 37,7 & 135 & 45,2 & 151 & 47,2 & 149 & 47,2 & 224 & 54,5 \\
\hline Pública e Privada & 3 & 1,0 & 2 & 0,7 & 4 & 1,3 & 6 & 1,9 & 3 & 0,7 \\
\hline TOTAL & 302 & 100,0 & 299 & 100,0 & 320 & 100,0 & 316 & 100,0 & 411 & 100,0 \\
\hline
\end{tabular}

Fonte: Dieese (2006, 2007, 2009), modificada.

Tabela 2 - Distribuição de grevistas nas esferas pública e privada. Brasil - 2004 a 2008

\begin{tabular}{|c|c|c|c|c|c|c|c|c|c|c|}
\hline \multirow{2}{*}{ Esfera/Setor } & \multicolumn{2}{|c|}{2004} & \multicolumn{2}{|c|}{2005} & \multicolumn{2}{|c|}{2006} & \multicolumn{2}{|c|}{2007} & \multicolumn{2}{|c|}{2008} \\
\hline & $\mathrm{n}^{\mathrm{O}}$ & $\%$ & $\mathrm{n}^{\mathrm{o}}$ & $\%$ & $\mathrm{n}^{\mathrm{o}}$ & $\%$ & $\mathrm{n}^{\mathrm{o}}$ & $\%$ & $\mathrm{n}^{\mathrm{o}}$ & $\%$ \\
\hline Pública & 826.074 & 64,0 & 1.380 .585 & 68,1 & 770.240 & 56,6 & 713.259 & 49,6 & 1.305 .683 & 63,9 \\
\hline Func. público & 791.920 & 34.154 & 61,3 & 2,6 & 1.137 .423 & 243.162 & 56,1 & 12,0 & 729.600 & 40.640 \\
\hline Empr. estatais & 53,6 & 3,0 & 546.955 & 166.304 & 38,0 & 11,6 & 1.103 .384 & 202.299 & 54,0 & 9,9 \\
\hline Privada & 249.258 & 19,3 & 484.915 & 23,9 & 388.673 & 28,6 & 641.766 & 44,6 & 603.441 & 29,5 \\
\hline Pública e Privada & 216.000 & 16,7 & 161.000 & 7,9 & 201.100 & 14,8 & 82.750 & 5,8 & 134.000 & 6,6 \\
\hline TOTAL & 1.291 .332 & 100,0 & 2.026 .500 & 100,0 & 1.360 .013 & 100,0 & 1.437 .769 & 100,0 & 2.043 .124 & 100,0 \\
\hline
\end{tabular}

Fonte: Dieese (2006, 2007, 2009), modificada.

dicações mais presentes nesse novo ciclo têm sido por ganho real de salário e por conquista ou majoração da Participação nos Lucros e Resultados (PLR). Reduziu-se o número de greves defensivas - por pagamento de salários atrasados, por respeito a direitos já existentes, etc. A frequência de ação ofensiva não é a mesma em todos os setores. No setor privado, por exemplo, esse tipo de ação é típico dos trabalhadores da indústria, enquanto as paralisações no setor de serviços são notadamente defensivas (Dieese, 2006).

Nos anos de 2004 e 2005, cerca de metade das greves apresentou a reivindicação de reajuste salarial. Em 2004, a reivindicação de pagamento de salário atrasado apareceu em 19\% das greves, ocupando o terceiro posto na lista de reivindica-

primeiro lugar, porque o termo “propositivo” está bastante associado, no cotidiano sindical e nos estudos acadêmicos sobre o assunto, a uma determinada estratégia: aquela do sindicalismo metalúrgico do ABC paulista. As estratégias desse sindicalismo, boa parte das vezes, incluem negociações que estão longe da luta por melhores condições de trabalho, novos direitos e melhorias salariais (Galvão, 1996), ao contrário do que observamos nesse novo ciclo de greves da década de 2000 . Em segundo lugar, porque não parece adequado opor "propositivo" e "defensivo", tal como faz a classificação do Dieese. O oposto de um sindicalismo propositivo seria aquele que se recusaria a fazer propostas; o que não nos parece ser o caso de quase nenhuma atividade sindical. Na prática e na semântica, o oposto de "defensivo" é, de fato, "ofensivo". ções. Já em 2005, a cobrança de salário atrasado caiu para o quinto posto nessa lista, com apenas $12 \%$ de ocorrências. Apenas no setor de serviços da esfera privada, a reivindicação de pagamento de salário atrasado mantém-se tão importante quanto a reivindicação por reajuste salarial. No conjunto do período 2004-2008, as reivindicações ofensivas estiveram presentes na grande maioria das greves - em porcentagem, $65 \%$ ou mais do total de greves de cada ano. Essa tendência é contrária àquela verificada na década de 1990, quando, embora as greves ocorressem em maior número, nelas predominavam as reivindicações de caráter defensivo, segundo o levantamento do Dieese (2008, p.32; 2009, p.4). Ou seja, na década de 1990, parece que os trabalhadores tiveram de correr muito apenas para lograr permanecer no mesmo lugar, enquanto que, na de 2000, com menos esforço, isto é, com um número menor de greves, estão logrando avançar em novas conquistas. A predominância das reivindicações ofensivas nas greves do quinquênio 2004-2008 aparece na Tabela 3 a seguir.

3. Podemos afirmar que os trabalhadores estão logrando avançar em novas conquistas porque essas greves mais ambiciosas em seus objeti- 
Tabela 3 - Distribuição de greves por caráter das reivindicaçõesBrasil - 2004 a 2008

\begin{tabular}{|c|c|c|c|c|c|c|c|c|c|c|}
\hline \multirow{2}{*}{ Caráter } & \multicolumn{2}{|c|}{2004} & \multicolumn{2}{|c|}{2005} & \multicolumn{2}{|c|}{2006} & \multicolumn{2}{|c|}{2007} & \multicolumn{2}{|c|}{2008} \\
\hline & $\mathrm{n}^{\mathrm{O}}$ & $\%$ & $\mathrm{n}^{\mathrm{o}}$ & $\%$ & $\mathrm{n}^{\circ}$ & $\%$ & $\mathrm{n}^{\circ}$ & $\%$ & $\mathrm{n}^{\mathrm{O}}$ & $\%$ \\
\hline Ofensiva & 197 & 65,2 & 207 & 69,2 & 217 & 67,8 & 209 & 66,1 & 284 & 69,1 \\
\hline Defensiva & 161 & 53,3 & 135 & 45,2 & 168 & 52,5 & 146 & 46,2 & 171 & 41,6 \\
\hline $\begin{array}{l}\text { pela manutenção das } \\
\text { condições vigentes }\end{array}$ & 54 & 17,9 & 72 & 24,1 & 110 & 34,4 & 61 & 19,3 & 72 & 17,5 \\
\hline $\begin{array}{l}\text { pelo cumprimento } \\
\text { de direitos }\end{array}$ & 107 & 35,4 & 70 & 23,4 & 87 & 27,2 & 101 & 32,0 & 118 & 28,7 \\
\hline Protesto & 28 & 9,3 & 50 & 16,7 & 49 & 15,3 & 48 & 15,2 & 53 & 12,9 \\
\hline Solidariedade & 2 & 0,7 & 2 & 0,7 & 2 & 0,6 & 1 & 0,3 & 1 & 0,2 \\
\hline Sem informação & 0 & - & 2 & 0,7 & 0 & - & 0 & - & 0 & - \\
\hline Número de greves & 302 & - & 299 & - & 320 & - & 316 & - & 411 & - \\
\hline
\end{tabular}

Fonte: Dieese (2007 e 2009) modificada.

Obs.: A última linha desta tabela representa o total de greves de cada ano. Ela não representa a soma das colunas, visto que uma mesma greve pode apresentar mais de um tipo de reivindicação.

vos têm sido, na sua maioria, bem-sucedidas na vindicação é insignificante, tanto para o ano de obtenção, total ou parcial das reivindicações que 2004, quanto para o ano de 2005 -apenas $7 \%$ em as motivaram.

As reivindicações que motivaram as greves 2004 e $6 \%$ em 2005 podem ser consideradas greves indubitavelmente derrotadas. Em 2007, apeforam, ao que tudo indica, total ou parcialmente, atendidas. Cerca de $90 \%$ delas conseguiram estabelecer negociação com os empregadores, e a pesquisa do Dieese constatou, para o ano de 2005, que $75 \%$ das greves para as quais se obteve esse tipo de informação terminaram com a obtenção de algumas ou de parte das reivindicações. O montante de greves que não logrou obter nenhuma reinas $6 \%$ das greves não obtiveram nenhuma satisfação. Em 2007, tiveram suas reivindicações atendidas, total ou parcialmente, $61 \%$ dos movimentos grevistas. Em 2008, tal como nos anos anteriores, o índice de obtenção de resultados positivos foi alto, alcançando 73\% (Dieese, 2009). De setor para setor, varia bastante o montante das greves que obtiveram algum sucesso. Os trabalhadores das

Tabela 4 - Distribuição dos reajustes salariais em comparação com o INPC-IBGE Brasil -1998 a 2008

\begin{tabular}{|c|c|c|c|c|c|c|c|c|}
\hline \multirow{2}{*}{ Ano } & \multicolumn{2}{|c|}{ Acima do INPC } & \multicolumn{2}{|c|}{ Igual ao INPC } & \multicolumn{2}{|c|}{ Abaixo do INPC } & \multicolumn{2}{|c|}{ Total } \\
\hline & $\mathrm{n}^{\mathrm{O}}$ & $\%$ & $\mathrm{n}^{\mathrm{o}}$ & $\%$ & $\mathrm{n}^{\mathrm{O}}$ & $\%$ & $\mathrm{~N}^{\circ}$ & $\%$ \\
\hline 1998 & 141 & 43,5 & 64 & 19,8 & 119 & 36,7 & 324 & 100 \\
\hline 1999 & 111 & 35,1 & 46 & 14,6 & 159 & 50,3 & 316 & 100 \\
\hline 2000 & 190 & 51,5 & 56 & 15,2 & 123 & 33,3 & 369 & 100 \\
\hline 2001 & 214 & 43,2 & 97 & 19,6 & 184 & 37,2 & 495 & 100 \\
\hline 2002 & 123 & 25,6 & 134 & 27,9 & 223 & 46,5 & 480 & 100 \\
\hline 2003 & 103 & 18,8 & 125 & 22,8 & 320 & 58,4 & 548 & 100 \\
\hline 2004 & 361 & 54,9 & 171 & 26 & 126 & 19,1 & 658 & 100 \\
\hline 2005 & 459 & 71,7 & 104 & 16,3 & 77 & 12 & 640 & 100 \\
\hline 2006 & 565 & 86,3 & 70 & 10,7 & 20 & 3,1 & 655 & 100 \\
\hline 2007 & 627 & 87,7 & 59 & 8,3 & 29 & 4 & 715 & 100 \\
\hline $2008 *$ & 548 & 77,6 & 74 & 10,5 & 84 & 11,9 & 706 & 100 \\
\hline \multicolumn{9}{|c|}{$\begin{array}{l}\text { Fonte: Lucio, Clemente Ganz } 2008 \text { "Balanço das negociações coletivas e das greves no Brasil no período 1998-2007" (Dieese, 2007, p.5). } \\
\text { *Fonte dos dados de 2008: Dieese (2009a). }\end{array}$} \\
\hline \multicolumn{9}{|c|}{ 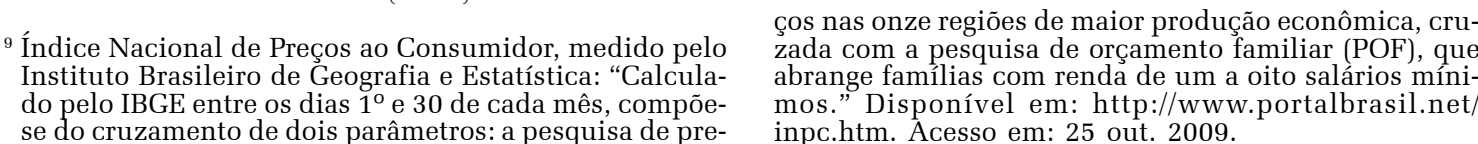 } \\
\hline
\end{tabular}


empresas estatais têm sido os mais bem-sucedidos nas ações grevistas (86\% delas tiveram suas reivindicações atendidas, total ou parcialmente). Esse percentual cai para 71\% das greves na esfera privada e para $50 \%$ nas greves do funcionalismo federal, estadual e municipal (Dieese, 2008). Os dados gerais de greves que obtiveram total ou parcialmente suas reivindicações para o quinquênio são os seguintes: 2004: 70\%; 2005: 75\%; 2006 : 75\%; 2007: 60\% e 2008: 73\%

Os dados sobre reajuste salarial também são muito significativos. Eles aparecem na Tabela $4 \mathrm{e}$ contemplam um período mais longo, permitindo algumas comparações.

Note-se que foi exatamente no ano de 2004, ano que estamos considerando o ponto inicial do atual ciclo de greves, que o número de acordos salariais com reajuste acima do INPC cresceu muito, saltando da faixa de 18 para 54\% dos acordos. A partir de então, esse montante continuou crescendo, atingindo a porcentagem impressionante de 87\% de acordos com reajuste acima da inflação no ano de 2007. Segundo o Dieese (2009a), para o ano de 2008, apurou-se que $88 \%$ das categorias lograram assegurar reajustes em patamar igual ou superior à taxa de inflação, índice igual àquele de 2005. ${ }^{10}$

4. Outra característica do ciclo de greves de 2004-2008 diz respeito à amplitude das greves e aos métodos de luta mais agressivos utilizados pelos trabalhadores. Em números, predominam as greves localizadas, porém as grandes greves de massa também têm ocorrido com certa frequência. Os grevistas realizaram, também, ações públicas para pressionar os empregadores.

Em 2005, ocorreram 25 greves que envolveram mais de 10 mil trabalhadores cada uma; des-

\footnotetext{
${ }^{10}$ No documento "Estudos e Pesquisas no 43: balanço das negociações e reajuste salariais em 2008" de 2009, o Dieese faz um série que vai desde o ano de 1996 até 2008, comparando os índices de reajuste salarial com o INPCIBGE do período. Desagregando os dados para uma comparação entre o período 1996-2003 e o período do novo ciclo de greves (2004-2008), temos o seguinte: a média anual de reajustes abaixo do índice INPC-IBGE para o período 1996-2003 foi 44\% das categorias, enquanto essa mesma média para o período 2004-2008 foi de $10,1 \%$ das categorias. Podemos, então, afirmar que uma das características do novo ciclo de greves é que os resultados da ação sindical têm sido muito mais favoráveis aos trabalhadores que no período anterior.
}

sas, nove greves contaram com mais de 50 mil grevistas. Em 2007, ocorreram quatorze greves que envolveram mais de 10 mil trabalhadores cada uma; dessas, sete greves contaram com mais de $50 \mathrm{mil}$ grevistas. Muitas dessas greves massivas são ações do funcionalismo público, principalmente pessoal da educação e da saúde. Porém elas ocorrem também em número significativo e em grande escala na esfera privada e nas empresas estatais. Vejamos apenas alguns exemplos.

Infelizmente, não temos esses dados para o ano de 2008. No que respeita ao quadriênio 2004/ 2007, porém, os dados são significativos. Tivemos uma greve nacional de metalúrgicos, que contou com 170 mil grevistas; uma greve estadual dos metalúrgicos paulistas, que contou com 190 mil grevistas; uma greve dos trabalhadores da construção civil paulista, que envolveu 130 mil grevistas; mais de uma greve dos trabalhadores do Correio, com cerca de 80 mil grevistas cada uma; mais de uma greve de petroleiros, que contou com cerca de 100 mil grevistas; greves de massa de bancários e outras. As greves massivas têm sido na sua quase totalidade ações ofensivas para conquista de aumentos reais e (ou) de novos direitos e melhores condições de trabalho.

Como dissemos, um número considerável de greves lançou mão de métodos de luta que exigem um nível de organização e de mobilização mais elevado e que dão maior visibilidade à ação sindical - atos públicos, passeatas, piquetes e ocupações.

A pesquisa do Dieese obteve a informação sobre atos públicos, passeatas, piquetes e ocupações. Em 2005, essas ocorrências foram registradas em 66 greves (22\% do total de greves do ano). Dessas 66 greves, em 39 delas os grevistas realizaram atos públicos, em 25 saíram em passeata, em vinte lançaram mão do piquete para manter a greve, oito greves foram acompanhadas de ocupação do local de trabalho, em cinco foram realizados acampamentos dos grevistas e em três os grevistas fizeram vigília. Em 2007, o número de greves nas quais os grevistas realizaram atos públicos subiu para 83, em 42 greves, os trabalhadores saíram em passeata, em vinte, lançaram mão do piquete, em dezenove, ocor- 
reu ocupação, em doze acampamentos dos grevistas e em duas os grevistas fizeram vigília. Isto é, as ações que dão visibilidade política e social à ação grevista e que endurecem o conflito com os empregadores cresceram muito entre 2005 e 2007.

5. A maioria das greves tem sido realizada pelos setores que são, há muito tempo, os setores mais mobilizados do movimento sindical - tais como os metalúrgicos, os petroleiros, os trabalhadores da construção civil, os bancários e os funcionários públicos, notadamente dos setores da educação e da saúde. O ciclo grevista de 2004-2008 parece indicar, portanto, que, as mudanças ocorridas no sindicalismo brasileiro não foram tão radicais como poderíamos ser levados a crer lendo os autores que insistem, de modo unilateral e genérico, na idéia da crise do sindicalismo como resultante da mutação tecnológica, da nova organização do processo de trabalho e da transformação na composição das classes trabalhadoras.

Outras características da fase anterior do sindicalismo brasileiro mantêm-se em vigência na atual fase de recuperação. Retomando para outras considerações alguns dos dados que já citamos, queremos destacar: a predominância, na esfera privada, das greves no setor industrial, com o setor de serviços ocupando uma posição secundária no quinquênio 2004/2008; a predominância, no setor industrial, das greves no ramo metalúrgico. No ano de 2005, 70\% das greves da indústria foram realizadas por metalúrgicos. No ano de 2007, duas grandes greves do operariado metalúrgico, uma nacional e outra no Estado de São Paulo, reuniram nada menos que 360 mil grevistas; os outros setores em destaque tampouco representam novidade: em 2005, 20\% das greves foram realizadas por trabalhadores da construção civil e 125 mil petroleiros entraram em greve. Em 2007, 130 mil trabalhadores da construção civil entraram em greve; no setor de serviços, há predominância dos bancários como trabalhadores sindicalmente mobilizados, dos trabalhadores do correio e dos trabalhadores em transporte, com destaque para o transporte urbano. Os trabalhadores do transporte coletivo urbano responderam por $45 \%$ das gre- ves no serviço privado em 2005. No ano de 2005, 160 mil bancários e 86 mil carteiros entraram em greve; predominância, no ramo metalúrgico, das greves nas montadoras de veículos; inatividade grevista em setores como o comércio, setor que permanece de importância muito pequena no movimento sindical apesar de reunir um contingente muito grande de trabalhadores. No quadriênio 2004-2007, o registro de greves pelo Dieese no setor do comércio variou entre nenhuma ou apenas uma greve em cada ano. ${ }^{11}$

Outro traço de continuidade aparece no fato de que as greves mantiveram-se, no geral, concentradas na Região Sudeste do país, particularmente no Estado de São Paulo.

Em 2005, 87\% das greves ocorreram na Região Sudeste; dessas, mais de 60\% tiveram lugar no Estado de São Paulo. Em 2007, o Sudeste respondeu por $83 \%$ das greves ocorridas em todo o país, mantendo-se o patamar elevadíssimo de concentração, apesar de notarmos uma pequena queda na participação relativa da Região Sudeste.

Se desagregarmos por setor, veremos que a predominância da Região Sudeste e de São Paulo ocorre na indústria e nos serviços. É nas greves do funcionalismo público estadual e municipal que se observa uma diferença importante. Essas greves se concentram na Região Nordeste. O NE foi responsável por $55 \%$ das 60 paralisações de funcionários estaduais ocorridas no ano de 2007 e por 45\% das 55 greves de funcionários municipais ocorridas no país no mesmo ano. No nível estadual e municipal, predominam amplamente as greves dos de professores e funcionários da educação. Esses dados podem ter dois significados: ou a transferência de plantas industriais e de demais empresas para as regiões periféricas do país não foi um fenômeno tão importante quanto pareceu a alguns observadores, ou então, apesar de essa transferência ter sido realmente grande, o

${ }^{11} \mathrm{O}$ documento do Dieese "Balanço das greves de 2008. Nota à imprensa” (http://cspb.org.br/UserFiles/files/ DIEESE_EST_PESQ 45_greves_2008_resumovalido.pdf Acesso em: $2 \overline{1} \cdot 10.2009$ ), não ap̃resenta o detalhamento das greves de 2008 por categoria profissional ou por região do país. Por isso, nesses quesitos, consideramos apenas o quadriênio 2004-2007. 
sindicalismo do Sudeste mantém-se muito mais organizado que o das demais regiões do país. Essas duas possibilidades não são excludentes.

6. Com exceção do ano de 2008, ocorreram mais greves no setor público do que no setor privado. Tal tendência, que deverá merecer a atenção do analista para os anos vindouros, vem se desenhando há bastante tempo, tendo se iniciado já no decorrer do ciclo grevista de 1978-1992.

No setor público, surgiram novidades nas mobilizações - por exemplo, a polícia federal, as polícias civil e militar, os funcionários do judiciário, do Banco Central, os auditores fiscais e alguns outros. Porém o sindicalismo do setor público apresenta traços visíveis de continuidade, como a predominância do funcionalismo estadual nos anos de 2004, 2005, 2006 e 2007 e, no funcionalismo estadual, destaque para professores e profissionais da saúde.

O estudo da fase atual do movimento sindical brasileiro pode requerer, mais que em outras épocas, a atenção para o conflito no local de trabalho. A substituição das greves por pequenas paralisações por setor no interior de uma mesma empresa - modalidade de ação que cresceu na Europa, e que cresceu, como já dissemos, inclusive devido às novas formas de organização do trabalho na empresa capitalista (Béroud, 2008) - pode, também, estar ganhando corpo no Brasil. Se confirmada essa hipótese, essa seria uma novidade importante da atual fase do sindicalismo brasileiro-um sindicalismo que, como se sabe, mantém-se, apesar de alguns avanços importantes nas últimas décadas, fundamentalmente fora do local de trabalho.

\section{CONSIDERAÇÕES FINAIS}

Buscamos, neste texto, fazer uma reflexão inicial sobre dois pontos interligados do debate sobre a atividade sindical no capitalismo contemporâneo: primeiro, fizemos um balanço preliminar do debate em torno da tese de declínio histórico do sindicalismo e de teses, no mais das vezes correlatas, de crise do movimento sindical; em seguida, e também de maneira preliminar, refleti- mos sobre os dados estatísticos de greves no Brasil levantados pelo Dieese. Nesses dois momentos do texto, buscamos apontar porque a tese sobre o declínio do sindicalismo nos parece um equívoco e levantamos argumentos sobre a necessidade de se analisar o contexto político, econômico e ideológico da atividade sindical. Indicamos que a ofensiva, retração ou refluxo desse movimento dependem de uma conjunção de fatores referentes às características do movimento sindical. Mas também, e principalmente, referentes ao contexto no qual esse movimento atua.

A década de 2000, com as alterações que trouxe nas conjunturas econômica, política e ideológica, pôde, justamente por isso, propiciar uma recuperação da atividade sindical no Brasil. Como vimos, essa recuperação não foi abalada, pelo menos até o presente momento, pela crise econômica de 2008. Segundo os dados do Dieese, verifica-se um aumento da proporção de greves no último trimestre de 2008, quando comparada a igual período dos anos anteriores; e essas greves mantiveram as mesmas características apontadas no quinquênio todo: foram greves ofensivas, por conquistas de novos direitos e (ou) ampliação dos já assegurados. As projeções do Dieese apontam que o ano de 2009 deve fechar com um número de greves próximo ao de 2008. Até junho de 2009, aquela instituição de pesquisa sindical registrou 250 greves e, embora a crise possa ter tido alguma responsabilidade no aumento do número de greves defensivas nos setores mais atingidos por demissões e dificuldades (autopeças e frigoríficos, por exemplo), um balanço prévio, com dados referentes a 100 greves, indica que, comparando-se com 2008, mais categorias conseguiram, pelo menos, a reposição inflacionária. A crise não parece ter afetado negativamente, pelo menos até esse ano de 2009, a atividade grevista e as negociações salariais. ${ }^{12}$

${ }^{12}$ As relações entre crise econômica e sindicalismo são complexas. No geral, os períodos de expansão são favoráveis ao sindicalismo, o contrário ocorrendo nos períodos de crise. Contudo, a história recente do capitalismo, inclusive no Brasil, mostra que o efeito da crise econômica sobre o movimento sindical pode não ser imediato. $\mathrm{Na}$ recessão de 1990-1992, apenas em 1992 observouse, no Brasil, uma queda grande na atividade sindical (Boito Jr., 1999; Noronha, 2009). 
Uma análise preliminar do panorama político e sindical brasileiro na atualidade parece indicar que, na década de 2000, o sindicalismo também foi uma agente importante na política nacional. As três maiores centrais sindicais brasileiras - Central Única dos Trabalhadores, Força Sindical e Central dos Trabalhadores do Brasil - apoiam o Governo Lula e recebem, em contrapartida, um tratamento político de força aliada e interlocutor legítimo. Nossa hipótese é de que o sindicalismo ocupa uma posição importante na sustentação política do governo, embora seja uma força subalterna no arranjo de poder vigente no país. O foco da política econômica do Governo Lula são os interesses da grande burguesia interna brasileira (Boito Jr., 2005).

O atual ciclo de greves no Brasil não é um fato isolado. A volta da greve geral de protesto na França - onde, somente no primeiro semestre de 2009 , foram realizadas duas grandes e muito bemsucedidas greves gerais em protesto contra a política de Nicolas Sarkozy -, a importância que o movimento sindical dos Estados Unidos teve na campanha eleitoral vitoriosa de Barack Obama nos EUA e as medidas recentemente tomadas por esse governo, retirando restrições que pesavam sobre o sindicalismo desde o governo Reagan, são fatos que podem ser tomados como prováveis indicadores de que o sindicalismo esteja superando a fase mais difícil que viveu em anos recentes.

Alguns intelectuais críticos, estudiosos do movimento operário, acabaram assimilando, nas entrelinhas e indiretamente, a idéia de um declínio irreversível do movimento sindical. Fizeram isso por falarem de modo genérico, impreciso e unilateral sobre a crise, e por apresentarem análises semelhantes àquelas que eram feitas pelos teóricos do declínio histórico do sindicalismo. Ao contrário daquelas análises, vemos que, na década de 2000, as alterações na conjuntura econômica, política e ideológica podem propiciar uma recuperação do sindicalismo.

(Recebido para publicação em novembro de 2009) (Aceito em março de 2010)

\section{REFERÊNCIAS}

BAUMARD, M.; BLANCHOT, M. Crise du syndicalisme. 2.ed. Paris: Hatier, 1994. 78p.

BÉROUD, S. et al. Entre grèves et conflits: les luttes quotidiennes au travail. Nozy-Le Grand, Fr: Centre d'études de l'emploi, 2008. 76p. (Rapport de recherché)

BOITO JR., A. Classe média e sindicalismo. In:

Estado, política e classes sociais. São Paulo: Unesp, 2007. p.223-245.

A burguesia no governo Lula. Crítica Marxista. Rio de Janeiro, n.21, p.52-76, 2005.

A crise do sindicalismo. In: SANTANA, M. A. RAMALHO, J. R. (Org.) Além da fábrica: trabalhadores, sindicatos e a nova questão social. São Paulo: Boitempo, 2003. p.319-333.

Política neoliberal e sindicalismo no Brasil. São Paulo: Xamã, 1999. 247p.

CAIRE, G. Introduction. Syndicalisme em crise? In: BIBES, G.; MOURIAUX, R. Les syndicats européens à l'épreuve. Paris : Presses de la Fondation Nationale des Sciences Politiques, 1990. p.15-46.

DIEESE. Balanço das greves em 2008. Nota à imprensa 2009. Disponível em: http://cspb.org.br/UserFiles/files DIEESE_EST_PESQ_45_greves_2008_resumovalido.pdf Acesso em: $2 \overline{1}$ out. $200 \overline{9}$

Estudos e pesquisas n.43: balanço das negociações e reajuste salariais em 2008. Disponível em: http://

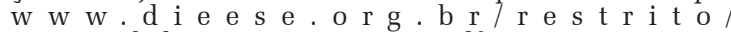
estPesq43balanconegociacao2008.pdf. Acesso em: 25 out. 2009a.

Balanço de greves. 2007. Disponível em: http://

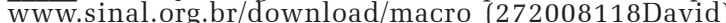
Greves2007.pdf. Acesso em: 15 mar. 2009

As greves em 2005. 2006. Disponível em: http:// www.mte.gov.br/observatorio/Prod032006.pdf. Acesso em: 15 mar. 2009.

FANTASIA, R. Spectaculaire victoire des camionneurs américains. Le Monde Diplomatique, Paris, out. 1997.

GALVÃO, A. Participação e fragmentação: a prática sindical dos metalúrgicos do ABC nos anos 90. 1990. 163f. Dissertação (Mestrado em Ciência Política) - Universidade Estadual de Campinas, 1990.

GUERRIN, D. Le mouvment ouvrier aux Etats-Unis. Paris Maspero. 1977. 174p.

HOBSBAWM, E. A era dos impérios, 1875-1914. 13.ed. Rio de Janeiro: Paz e Terra, 2009. 600p.

LABBÉ, D.; CROISAT, M. La fin des syndicats? Paris: L'Harmattan, 1992. 236p.

LEITE, M. P. O futuro do trabalho: novas tecnologias e subjetividade operária. São Paulo: Scritta, 1994. 331p.

LOCKWOOD, D. El trabajador de la clase media. Madri: Aguilar, 1962. 234p.

LÚCIO, C. G. Balanço das negociações coletivas e das greves no Brasil no período 1998-2007. Disponível em: http://www.ibret.org/2conferencia/Apresentacoes/ Clemente _T.pdf. Acesso em: 15 mar. 2009.

MARCELINO, P. R. P. Terceirização e ação sindical. A singularidade da reestruturação do capital no Brasil. 2008. 373f. Tese (Doutorado em Ciências Sociais) - Universidade Estadual de Campinas, 2008.

MARTINS FILHO, J. R. Movimento estudantil e ditadura militar, 1964-68. Campinas: Papirus, 1987. 247p. 
MARX, K.; ENGELS, F. Sur le yndicalisme. Paris: Maspero, 1972. 73p.

MOURIAUX, R. Le syndicalisme en France depuis 1945. Paris: La Découverte, 1994. 125p.

Le syndicalisme français: combien de divisions? Mouvements. [S.l.], n.43, p.71-76. 2006.

NORONHA, E. G. Ciclo de greves, transição política e estabilização no Brasil, 1978-2007. Lua Nova, São Paulo, n.76, p.119-168, 2009 .

et al. Explicações para um ciclo excepcional de greves: o caso brasileiro. In: INTERNATIONAL greves: O caso brasileiro. In: INTERNATIONAL international.pitt.edu/ LASA98/GarutiNoronha-GebrineElias.pdf. Acesso em: 15 mar. 2009
PERRIN, E. Syndicats et colletifs face à la precarité. 2004. Disponível em: ttp://multitudes.samizdat.net/Syndicatset-colletifs-face-a-la.html. Acesso em: 20 dez. 2006.

POCHMANN, M. Adeus à CLT? O "eterno" sistema corporativo de relações de trabalho no Brasil. Novos Estudos, São Paulo, n.50, p.149-166, 1998.

POIRIER, F.; RAVIER, J. P. La crise syndicale en Grande-Bretagne. In: BIBES, G.; MOURIAUX, R. (Orgs.) Les syndicats européens à l'épreuve. Paris: Presses de la Fondation Nationale des Sciences Politiques, 1990. p.69-95.

RODRIGUES, L. M. Destino do sindicalismo. São Paulo: Edusp/Fapesp, 2002. 335p. 


\section{DID UNIONISM LEAVE THE CRISIS BEHIND? a new round of strikes in the 2000 s}

\author{
Armando Boito Jr. \\ Paula Marcelino
}

The aim of this paper is to resume, in an indicative and preliminary order, the debate on the crisis or the historical decline of trade unionism. The question we want to raise is this: union activity, in the 2000s, is indicative that the Brazilian trade unions overcame their crisis? Our text analyzes a cycle of strikes under way in Brazil since 2004, stressing, among other elements, the number of strikes and strikers, the offensive nature of these strikes and the victories that workers have been obtaining in their demands. We support the hypothesis, still under investigation, that union activity in Brazil in the 2000s is a very strong indicator of the mistake in the thesis of historical decline of unionism.

KEYwORDS: unions, strikes, crisis, Brazil.

\section{LE SYNDICALISME A-T-IL LAISSÉ LA CRISE DERRIERE LUI? un nouveau cycle de grèves dans les années 2000}

\author{
Armando Boito Jr \\ Paula Marcelino
}

Le but de cet article est de reprendre, de manière préliminaire et indicative, le débat concernant la crise ou le déclin historique du mouvement syndical. La question que nous voulons soulever est la suivante: l'activité syndicale des années 2000 est-elle un indice capable de montrer que le syndicalisme brésilien a dépassé la crise ? Notre article analyse le cycle des grèves qui ont eu lieu au Brésil depuis 2004 et souligne, entre autres éléments, le nombre de grèves et de grévistes, le caractère offensif de ces grèves et les résultats obtenus par les travailleurs suite à leurs revendications. Notre hypothèse, toujours à l'étude, est que l'activité syndicale au Brésil, dans les années 2000, est un indicateur important de l'équivoque concernant la thèse du déclin historique du syndicalisme.

MoTS-CLÉS: syndicalisme, grèves, crise, Brésil.

Armando Boito Jr. -Doutor em Sociologia. Pós-doutorado (Fondation Nationale des Sciences Politiques - FNSP, Paris) e Professor Titular de Ciência Política da Unicamp. Desenvolve pesquisa sobre as relações de classe no capitalismo neoliberal no Brasil e na América Latina. Editor da revista Crítica Marxista e um dos fundadores do Centro de Estudos Marxistas (Cemarx) do IFCH-Unicamp. Pesquisou o sindicalismo e a política brasileira e, mais recentemente, tem pesquisado também na área de teoria política e marxismo. Publicou, dentre outros: $O$ sindicalismo de Estado no Brasil - uma análise crítica da estrurtura sindical (Editoras Hucitec e Unicamp); Política neoliberal e sindicalismo no Brasil (Editora Xamã), O Sindicalismo na política brasileira (Editora IFCH-Unicamp) e Estado, política e classes sociais (Editora da Unesp). É organizador ou co-organizador de diversas coletâneas sobre a teoria marxista e o movimento operário: A obra teórica de Marx - atualidade, problemas e interpretações(Editora Xamã); A Comuna de Paris na História (Editora Xamã); Marxismo e Ciências Humanas (Editora Xamã) e Marxismo e socialismo no século XXI (Editora Xamã).

Paula Marcelino - Pós-doutoranda em Ciência Política na Unicamp. Trabalha com temas relacionados à situação e à ação dos trabalhadores: classes sociais reestruturação produtiva, neoliberalismo, precarização do trabalho, ação sindical e crise do sindicalismo. Publicou, entre outros textos, o livro: A logística da precarização: terceirização do trabalho na Honda do Brasil, pela editora Expressão Popular (São Paulo/SP), em 2004; com primeira reimpressão em março de 2009. 